\title{
En relación con la publicación de reportes de casos
}

\section{René Agustín Flores-Franco}

Instituto Mexicano del Seguro Social, Hospital General Regional de Zona 1, Unidad "Morelos", Departamento de Medicina Interna, Chihuahua, Chihuahua, México

He leído con interés el artículo editorial de la doctora Rodríguez-Velasco publicado recientemente ${ }^{1}$ y en el que acertadamente defiende la publicación de los reportes de casos en las revistas médicas. Al respecto quisiera ampliar sus comentarios.

No soy investigador y mi habilidad como tal sería únicamente la que persigo durante mi práctica clínica cotidiana al aplicar el método científico durante el examen médico de los pacientes. En la sección específica de las revistas médicas donde se incluyen los reportes de casos, los médicos no investigadores tenemos la oportunidad de expresarnos. El objetivo de cualquier investigación es resolver un problema y para hacerlo no necesariamente se utiliza una metodología cuantitativa. Muchos aspectos de la vida profesional y personal no pueden ser explicados únicamente con números o con base en la evidencia. La metodología cualitativa para abordar un problema es extremadamente humanística y se enfoca en cómo el individuo percibe sus experiencias y creencias y cómo sus interacciones con otros influyen en esas actitudes y valores. ${ }^{2}$

Un investigador cualitativo interpreta situaciones con descripciones y consideraciones personales con el único objetivo de obtener un mejor entendimiento de una determinada condición humana, tomando en cuenta el entorno natural donde se desenvuelve mediante un análisis inductivo. ${ }^{2}$ Esta es precisamente la metodología utilizada en el reporte de casos y el principio básico de una tendencia actual hacia la práctica de una medicina conductual. ${ }^{3}$

El reporte de casos es el complemento ideal de la investigación cuantitativa debido a que pone en práctica sus resultados en ambientes reales. Por lo anterior, considero injusto que no sea ponderado en forma similar a la información obtenida mediante una investigación cuantitativa. Una publicación científica con validez requiere evaluación por parte de revisores expertos en el tema, información organizada que incluya una hipótesis, una metodología y un análisis de sus resultados y ser expresada en un formato particular en las revistas. ${ }^{4}$ Todos estos elementos están considerados en la publicación de reporte de casos.

\section{Bibliografía}

1. Rodríguez-Velasco A. El dilema de los editores: ¿debe o no aceptarse el reporte de casos para publicación? Gac Med Mex 2018;154:149-151.

2. Pitney WA, Parker J. Qualitative research in physical activity and the health professions. EE.UU.: Human Kinetics; 2009.

3. Feldman MD, Christensen JF. Behavioral medicine: a guide for clinical practice. EE.UU.: McGraw-Hill; 2014.

4. Matthews JR, Matthews RW. Successful scientific writing. A step-by-step guide for the biological and medical sciences. EE.UU.: Cambridge University Press; 2008. 